\title{
Potential Therapeutic Action of Adiponectin in Duchenne Muscular Dystrophy
}

\author{
Michel Abou-Samra, Raphaël Boursereau, Sophie Lecompte, Laurence Noel, and Sonia M. Brichard
}

From the Endocrinology, Diabetes and Nutrition Unit, Institute of Experimental and Clinical Research, Medical Sector, Catholic University of Louvain, Brussels, Belgium

\author{
Accepted for publication \\ February 27, 2017. \\ Address correspondence to \\ Sonia M. Brichard, M.D., \\ Ph.D., Endocrinology, \\ Diabetes and Nutrition Unit, \\ Institute of Experimental and \\ Clinical Research, UCL/EDIN \\ B1.55.06 - Ave Hippocrate \\ 55, Harvey 55, B-1200 Brus- \\ sels, Belgium. E-mail: sonia. \\ brichard@uclouvain.be.
}

\begin{abstract}
Adiponectin ( $\mathrm{ApN})$ is a hormone that exhibits anti-inflammatory effects on skeletal muscle exposed to acute and chronic inflammation. We have previously tested the implication of ApN in Duchenne muscular dystrophy (DMD) using mdx mice, a model of DMD, and by generating transgenic mdx mice overexpressing $\mathrm{ApN}$. We showed that $\mathrm{ApN}$ can act as a preventive agent and delay disease progression by reducing muscle inflammation/injury and improving force/myogenesis. Herein, we took an opposite approach and crossed $\mathrm{mdx}$ mice with ApN knockout mice, to obtain mdx mice with ApN depletion. The aims were to test whether ApN deficiency could worsen the $\mathrm{mdx}$ phenotype and whether ApN supplementation can reverse several muscle abnormalities once the disease is settled. $\mathrm{mdx}$-knockout mice exhibited lower muscle force/endurance as well as increased muscle damage when compared to regular $\mathrm{mdx}$ mice. Local administration of the ApN gene significantly reduced the expression of several oxidative stress/inflammatory markers and increased the expression of myogenic markers in the skeletal muscle. Finally, the presence of $A p N$ markedly reduced the activity of $N F-\kappa B$, a key player in muscle inflammation and myogenesis. ApN proves to be a powerful protector of the skeletal muscle capable of reversing the disease progression, thus making it a potential therapeutic agent for DMD. (Am J Pathol 2017, 187: 1577-1585; http://dx.doi.org/10.1016/j.ajpath.2017.02.018)
\end{abstract}

Duchenne muscular dystrophy (DMD) is an X-linked genetic disorder that results in muscle degeneration and weakness. It is the most devastating type of muscular dystrophy and can affect approximately 1 in 3600 boys. ${ }^{1}$ DMD is caused by a defective gene that encodes for dystrophin, a protein that provides structural stability and integrity to muscle fiber membrane. ${ }^{2}$ The absence of dystrophin in muscle fibers leads to membrane fragility and high susceptibility to injury as well as severe inflammation/oxidative stress, all resulting in significant damage and necrosis. Chronic damage and repair cycles lead to fibrosis and weakness. ${ }^{1}$ Even though dystrophin deficiency is the main cause of DMD, it is the chronic inflammation that likely aggravates the disease. ${ }^{3}$

Adiponectin $(\mathrm{ApN})$ is a hormone abundantly secreted by adipocytes under normal conditions. ApN has high circulating blood levels but is significantly decreased in obese individuals and in patients meeting the criteria for the metabolic syndrome. ${ }^{4} \mathrm{ApN}$ is well known today to exert insulinsensitizing, fat-burning, and anti-inflammatory/antioxidative stress properties, in a variety of cell types, including the skeletal muscle, thus counteracting different aspects of the metabolic syndrome. ${ }^{4-7}$ Skeletal muscle is a main target tissue for $\mathrm{ApN}$, where adiponectin receptor 1 serves as its main receptor. ${ }^{8}$ In fact, muscles of mice with complete ApN deficiency [ApN knockout $(\mathrm{KO})]$ are insulin resistant and display high susceptibility to inflammation/oxidative stress and apoptosis. These abnormalities were further worsened by an acute or a chronic inflammatory challenge (ie, lipopolysaccharides injection or high-fat diet) but were then corrected after local electrotransfer of the ApN gene. ${ }^{5,6}$ In addition, mice with muscle-specific disruption of adiponectin receptor 1 also show decreased muscle insulin sensitivity,

\footnotetext{
Supported by a Belgian Telethon grant (S.M.B.), a French Association against Myopathies (The French Muscular Dystrophy Association Téléthon) grant (S.M.B.), the Foundation of Scientific and Medical Research grants 1.5097.12 and T.0212.13 (S.M.B.), and the General Division of Scientific Research grant ARC 12-17/047 (S.M.B.).

Disclosures: None declared.
} 
mitochondrial content, and oxidative metabolism, as well as enhanced cellular stress and a limited exercise capacity. ${ }^{9}$

We have previously shown that $\mathrm{ApN}$ could be a preventive agent powerful enough to counterbalance severe inflammation/oxidative stress and grave muscle damage in dystrophic muscles of mdx mice (a murine model of DMD). ${ }^{10}$ Furthermore, ApN was able to enhance the myogenic program and even muscle strength and endurance. This was demonstrated in our own mouse model (mdx-ApN), where transgenic mdx mice can start overexpressing ApN with the early onset of the disease. ${ }^{10}$

The aims of this work were first to study whether ApN deficiency could aggravate the dystrophic phenotype in $\mathrm{mdx}$ mice, and second to test if ApN supplementation can be a curative strategy capable of protecting the skeletal muscle, even after the dystrophic lesions have already begun. For this matter, we crossed mdx mice with ApN KO mice to obtain mdx mice with $\mathrm{ApN}$ depletion (mdx-KO). These mice were subjected to in vivo functional tests to measure their force, endurance, and muscle damage. Furthermore, these mice were supplemented with the $\mathrm{ApN}$ gene by electrotransfer to explore muscle inflammation/oxidative stress as well as muscle regeneration in the presence of ApN.

\section{Materials and Methods}

\section{Animals}

Adiponectin $\mathrm{KO}$ mice, which are characterized by a generalized lack of ApN, were obtained from ${ }^{11}$ and maintained on a C57BL/6J background. C57BL/6J mice were used as wildtype (WT) controls. C57BL/10scSn mdx mice (murine model of Duchenne muscular dystrophy) were purchased from Jackson Laboratory (Bar Harbor, ME). KO and mdx mice were crossed together to obtain in $\mathrm{F}_{2}, \mathrm{mdx}$ mice with a general lack of $\mathrm{ApN}$ (mdx-KO mice). These mdx-KO mice were compared to $\mathrm{mdx}$ mice, which have the same mixed genetic background. Only male mice were studied. WT mice on a pure $(\mathrm{C} 57 \mathrm{BL} / 6 \mathrm{~J})$ or on a mixed genetic background ${ }^{10}$ behaved similarly when in vivo studies of global force, resistance, or muscle damage were tested.

These animals were maintained under a standard laboratory chow and housed at a constant temperature $\left(22^{\circ} \mathrm{C}\right)$ with a fixed 12 hours light -12 hours dark cycle. At 8 weeks of age, the four groups (WT, KO, mdx, and mdx-KO mice) were either sacrificed in the basal state (between 9 and $11 \mathrm{Am}$ ) or after in vivo functional tests. Blood samples were saved. Pairs of different muscles were weighed, frozen in liquid nitrogen, and stored at $-80^{\circ} \mathrm{C}$ for subsequent analyses.

In an additional experiment, muscle transfer of the ApN gene was performed in anesthetized 9-week-old mdx-KO mice by injection with an ApN cDNA-containing plasmid (pcDNA-ApN) followed by electroporation in one tibialis anterior (TA), the contralateral muscle being electroporated with a control plasmid (pcDNA). ApN was detected only in the muscle injected with the pcDNA-ApN and not in the contralateral one, nor in circulation. ${ }^{5}$ Mice were sacrificed 12 days after, and the TA muscles were collected and processed as described above. TA muscles were used to evaluate the effects of muscle electrotransfer of the $\mathrm{ApN}$ gene on inflammation/oxidative stress markers as well as on myogenic markers in mdx-KO mice.

All procedures were approved by the Ethical Committee for Animal Experimentation from the Medical Sector at the Catholic University of Louvain (Brussels, Belgium).

\section{In Vivo Studies of Global Force or Resistance}

Mice were submitted to three main tests: wire test, grip test, and eccentric exercise test.

\section{Wire Test}

Animals were suspended by their limbs from a 1.5 -mm-thick, $60-\mathrm{cm}$-long metallic wire at $45 \mathrm{~cm}$ above soft ground. The time (second) until the mouse completely released its grasp and fell down was recorded. Three trials were performed per session, with a 15 -minute recovery period between trials. The maximum time per trial was set to 180 seconds. For each mouse, the scores of the three trials were averaged. ${ }^{12}$

\section{Grip Test}

The grip strength test measures the muscle strength of combined forelimb and hindlimb muscles. Limb strength was recorded using a grid connected to a sensor (PanlabBioseb, Vitrolles, France). The mice were gently laid on the top of the grid so that their paws can grip the grid. Then, mice were pulled back steadily until the grip was released down the complete length of the grid. Each test was repeated three times at an interval of 15 minutes. Results are presented as the mean of the three values of force recorded, related to body weight. ${ }^{13}$

\section{Eccentric Exercise}

The mice were subjected to a downhill running exercise on a treadmill with a downward inclination of 15 degrees, and at a speed of $10 \mathrm{~m} /$ minute for 10 minutes. This training was repeated daily for 3 days, and the mice were sacrificed 1 hour after the third session and 24 hours after the Evans Blue Dye (EBD) injection. ${ }^{16}$ Six different muscles were studied: biceps brachii and triceps brachii from the forelimbs; TA, gastrocnemius, extensor digitorum longus, and soleus from the hindlimbs.

\section{Quantification of Muscle Damage Markers in Plasma}

Plasma creatine kinase $(\mathrm{CK})$ and lactate dehydrogenase (LDH) activities were quantified to evaluate skeletal muscle damage as injured muscles release CK and LDH into the bloodstream at high levels. Kits were based on colorimetric methods (Gentaur, Kampenhout, Belgium). CK and LDH activities were expressed as IU/L. 

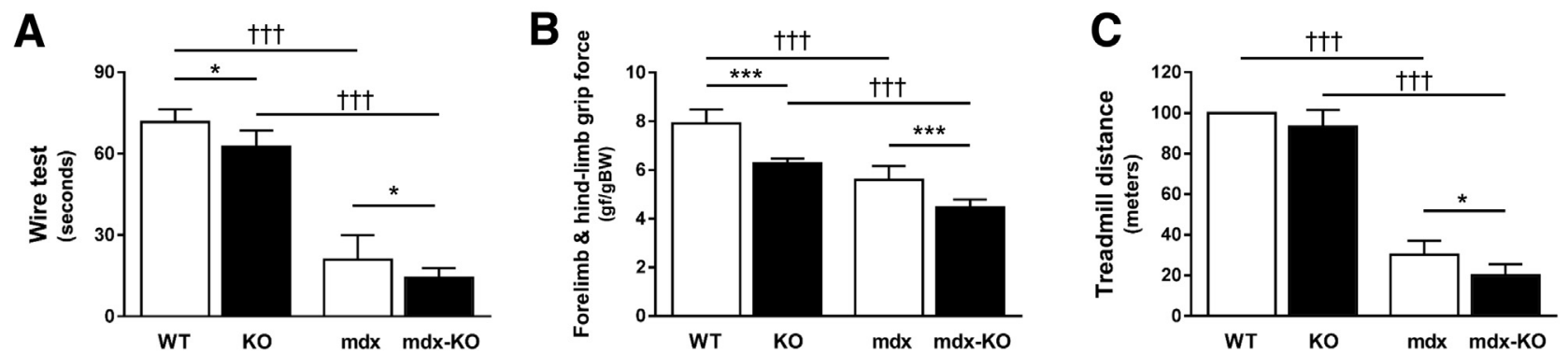

Figure 1 Effects of adiponectin deficiency on global force and resistance of $\mathrm{mdx}$ mice. Functional in vivo studies were performed in mice from the four groups: wild-type (WT) mice, adiponectin knockout (KO) mice, regular mdx mice ( $\mathrm{mdx}$ ) and $\mathrm{mdx}$ mice with a general lack of ApN (mdx-K0). A: The animals were subjected to a wire test where they were suspended by their limbs and the time (in seconds) until they completely released the wire and fell down was recorded. B: The mice were also lowered on a grid connected to a sensor to measure the muscle force of both their forelimbs and hindlimbs; data were then expressed in gram-force relative to body weight ( $\mathrm{gf} / \mathrm{gBW})$. C: Mice were submitted to a downhill treadmill exercise for 10 minutes during 3 consecutive days. On the third session, the covered distance (meters) was measured for each mouse, $100 \mathrm{~m}$ being the maximal distance. Data are expressed as means \pm SD $(\mathbf{A}-\mathbf{C}) . n=9$ mice per group $(\mathbf{A}-\mathbf{C}) .{ }^{*} P<0.05,{ }^{* *} P<0.001$ effect of ApN deficiency; ${ }^{\dagger \dagger \dagger} P<0.001$ effect of dystrophin deficiency.

\section{Evaluation of Muscle Injury after in Vivo Staining with EBD}

EBD irreversibly binds to plasma albumin in vivo, and on injury, the complex leaks into the surrounding tissues. ${ }^{14,15}$ EBD (Sigma-Aldrich, Bornem, Belgium) was dissolved in phosphate-buffered saline, sterilized by filtration through a membrane with a pore size of $0.2 \mu \mathrm{m}$, and kept at $4^{\circ} \mathrm{C}$. The dye solution was injected i.p. into the mice ( $1 \mathrm{mg}$ dye $/ 0.1 \mathrm{~mL} / 10 \mathrm{~g}$ body weight). The mice were sacrificed 24 hours later. ${ }^{16}$

EBD was extracted from powdered muscle using dimethylformamide, and the absorbance was read spectrophotometrically at $620 \mathrm{~nm}$. The extravasated EBD concentration was calculated against a standard curve and was expressed as nanogram of EBD/mg muscle weight. ${ }^{15}$

\section{Electrotransfer of Adiponectin Gene into Muscle}

\section{Expression Plasmid and DNA Preparation}

The pcDNA-ApN construct was generated by inserting the mouse full-length ApN cDNA ${ }^{17}$ into the pcDNA3.1D/V5His-TOPO vector (Invitrogen, Gent, Belgium). An empty plasmid, pcDNA, was used as control. Plasmids were amplified in Escherichia coli top 10 F' (Invitrogen), purified with an EndoFree plasmid giga kit (Qiagen, Venlo, the Netherlands), and were then stocked at $-20^{\circ} \mathrm{C}$.

\section{DNA Injection and Electroporation}

Thirty microliter of each plasmid solution $(2 \mu \mathrm{g} / \mu \mathrm{L})$ was injected into each TA. Muscles were then electroporated using transcutaneous electric pulses (eight square-wave pulses of $200 \mathrm{~V} / \mathrm{cm}$ and 20 milliseconds per pulse at 2 $\mathrm{Hz}$ ) that were applied by two 8-mm spaced electrodes. Pulses were delivered by a Cliniporator system (Cliniporator; IGEA, Carpi, Italy), as described. ${ }^{5,6}$ Mice were sacrificed 12 days after.

\section{Immunohistochemistry of Markers of Inflammation and Oxidative Stress}

TA muscle samples were fixed in $10 \%$ formalin for 24 hours and then embedded in paraffin. Sections $(5 \mu \mathrm{m}$ thick) were processed, as previously described, ${ }^{10}$ using rabbit polyclonal antibodies directed against peroxiredoxin 3 (dilution, 1:500; incubation, 2 hours 30 minutes; gift from Bernard Knoops, University of Louvain, Brussels, Belgium $\left.^{18}\right)$, 4-hydroxy-2-nonenal $(1: 100 ; 2$ hours 30 minutes), tumor necrosis factor- $\alpha$ (1:100; 2 hours 30 minutes), IL-1 $\beta$ (1:200; 2 hours 30 minutes), and phospho-NF- $\mathrm{B}$ p65 (phosphor Ser536 P-p65; 1:100; 2 hours 30 minutes) (all from Abcam, Cambridge, UK). Rat monoclonal antibodies directed against markers of macrophages [cluster of differentiation 68 (CD68)] (1:100; 2 hours 30 minutes; Abcam) and ApN (1:5000; 2 hours 30 minutes; Bio-Connect) were also used. Before immunostaining, sections were submitted to heat-mediated antigen retrieval using a microwave oven and Tris-citrate buffer ( $\mathrm{pH}$ 6.5). Binding of antibodies was detected by applying for 30 minutes at room temperature a second antibody, which was a biotinylated goat anti-rabbit IgG $(\mathrm{H}+\mathrm{L})$ or a biotinylated rabbit anti-rat $\operatorname{IgG}(\mathrm{H}+\mathrm{L})$ (Labconsult, Brussels, Belgium). Peroxidase activity was revealed with 3,3'-diaminobenzidine (Life Technologies, Gent, Belgium), which produces a brown staining. For each marker, all slides were treated simultaneously for immunohistochemistry analysis and 3,3'-diaminobenzidine revelation, and then analyzed together. Immunohistochemical controls were performed by omission of the first antibody or of the first and second antibodies or by using preimmune serum. For quantification of NF- $\kappa \mathrm{B}$ expression, the percentage of immunolabeled nuclei was determined after counting an average of 1500 fiber nuclei per slide for each mouse. For peroxiredoxin 3, 4-hydroxy-2-nonenal, tumor necrosis factor- $\alpha$, IL-1 $\beta$, and CD68, whole muscle sections were scanned using the Leica SCN400 slide scanner (Leica 

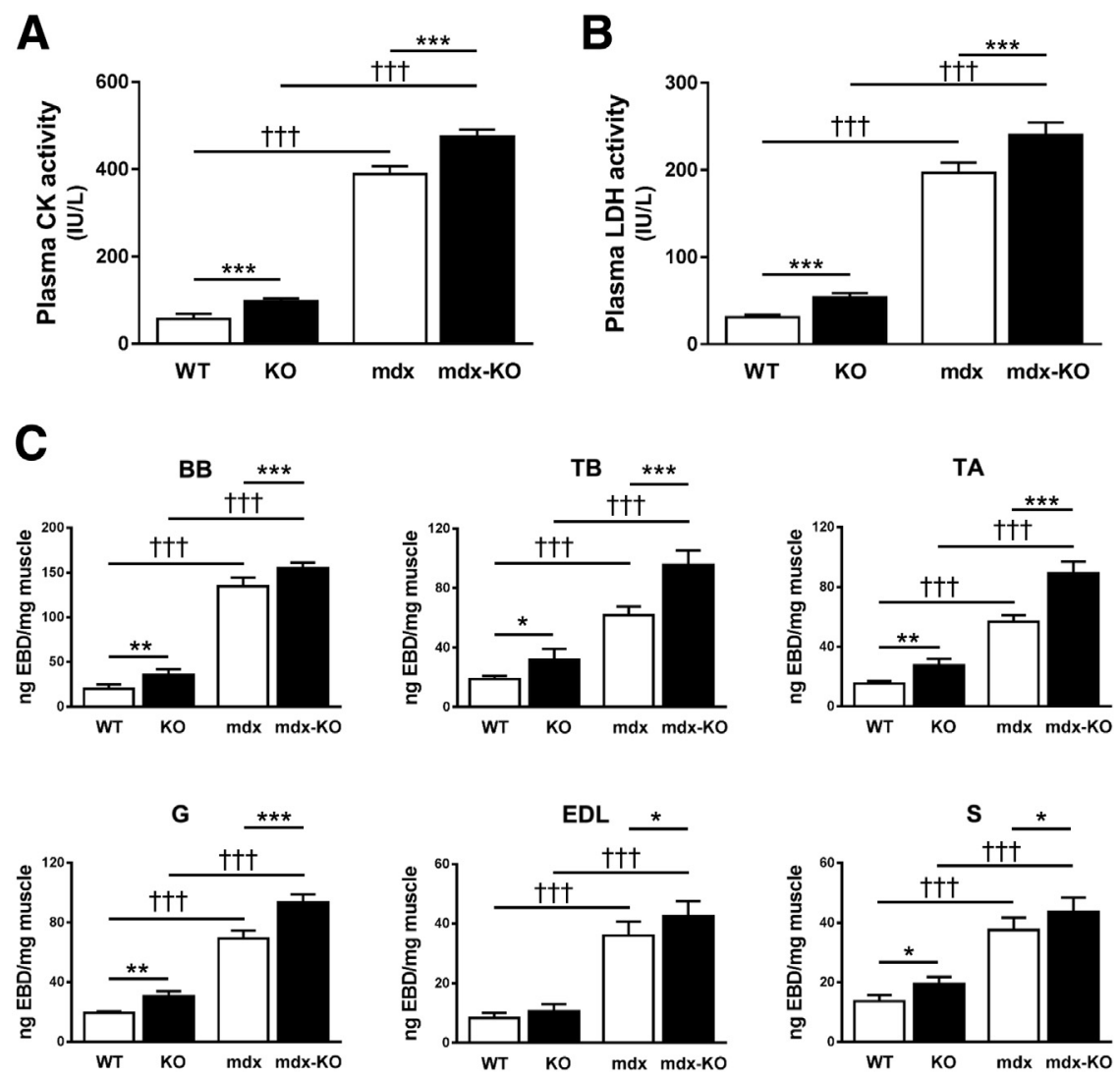

Figure 2 Effects of adiponectin deficiency on muscle injury in $\mathrm{mdx}$ mice. Muscle injury was assessed first by plasma activity of creatine kinase (CK) and lactate dehydrogenase (LDH) expressed as IU/L (basal state) (A and $\mathbf{B}$ ) and second by using Evans Blue Dye (EBD) (C). Quantification of EBD extravasation was measured in six different muscles after exercise [biceps brachii (BB), triceps brachii (TB) from the forelimbs, tibialis anterior $(T A)$, gastrocnemius $(G)$, extensor digitorum longus (EDL), and soleus (S)] and was quantified by spectrophotometry. Data are expressed as nanogram of EBD/mg muscle weight. $n=9$ mice per group (A and $\mathbf{B}) ; n=6$ mice per group (C). ${ }^{*} P<0.05,{ }^{*} P<0.01$, and $* * * P<0.001$ effect of ApN deficiency; ${ }^{\dagger \dagger} P<0.001$ effect of dystrophin deficiency. K0, adiponectin knockout mice; $m d x$, regular $m d x ; m d x-K 0, m d x$ mice with a general lack of ApN; WT, wild-type mice.
Microsystems, Diegem, Belgium), and then the percentage of 3,3'-diaminobenzidine surface area within muscle fibers was quantified using the Tissue Image Analysis 2.0 (Leica Microsystems).

\section{Western Blotting and Immunoprecipitation}

Skeletal muscle was homogenized in a lysis buffer supplemented with $1 \%$ protease/phosphatase inhibitor cocktail (all from Cell Signaling Technology, BIOKE, Leiden, the Netherlands). Immunoblotting was performed as reported ${ }^{10}$ by using rabbit polyclonal antibodies directed against myogenin (Bio-Connect), Mrf4, Myh3 (both from Abcam), and actin (Sigma). Signals were revealed by enhanced chemiluminescence, then quantified and normalized to those of actin, using ImageJ software version $1.48 \mathrm{v}(\mathrm{NIH}$, Bethesda, MD; http://imagej.nih.gov/ij).

\section{RNA Extraction and Real-Time Quantitative RT-PCR}

RNA was isolated from mouse TA muscles with TriPure reagent (Roche Diagnostics, Vilvoorde, Belgium). One to two micrograms of total RNA were reverse transcribed, and 40 to $80 \mathrm{ng}$ total RNA equivalents were amplified using an iCycler iQ real-time PCR detection system (Bio-Rad Laboratories, Nazareth, Belgium). ${ }^{10}$ Real-time quantitative RT-PCR primers for mouse cyclophilin, ApN, IL-10, Myh1, Myh7, Myh6 (Mrf4), and myogenin were used as reported. ${ }^{10}$
The $\mathrm{C}_{\mathrm{T}}$ values were measured in separate tubes and in duplicate. The identity and purity of the amplified product were checked by electrophoresis on agarose minigels, and the melting curve was analyzed at the end of the amplification. To ensure the quality of the measurements, each plate included a negative control for each set of primers.

\section{Statistical Analysis}

Results are means \pm SD for the indicated number of mice. When the four groups of mice (WT, KO, mdx, and mdx-KO) were compared, the effects of $\mathrm{ApN}$ and dystrophin deficiencies were assessed by two-way analysis of variance with $\mathrm{F}$ test, followed by post hoc two-by-two comparisons with Bonferroni correction for multiple comparisons (Prism 6; Graphpad Software, San Diego, CA). Comparisons between two conditions (effects of electrotransfer with ApN plasmid versus empty plasmid) from a given mdx-KO mouse were performed using two-tailed paired $t$-test (Prism 6). Differences were considered statistically significant at $P<0.05$.

\section{Results}

Effects of Adiponectin Deficiency on Global Force and Resistance

Global muscular force was evaluated using in vivo functional tests: the wire and the grip tests. The first test gives an 


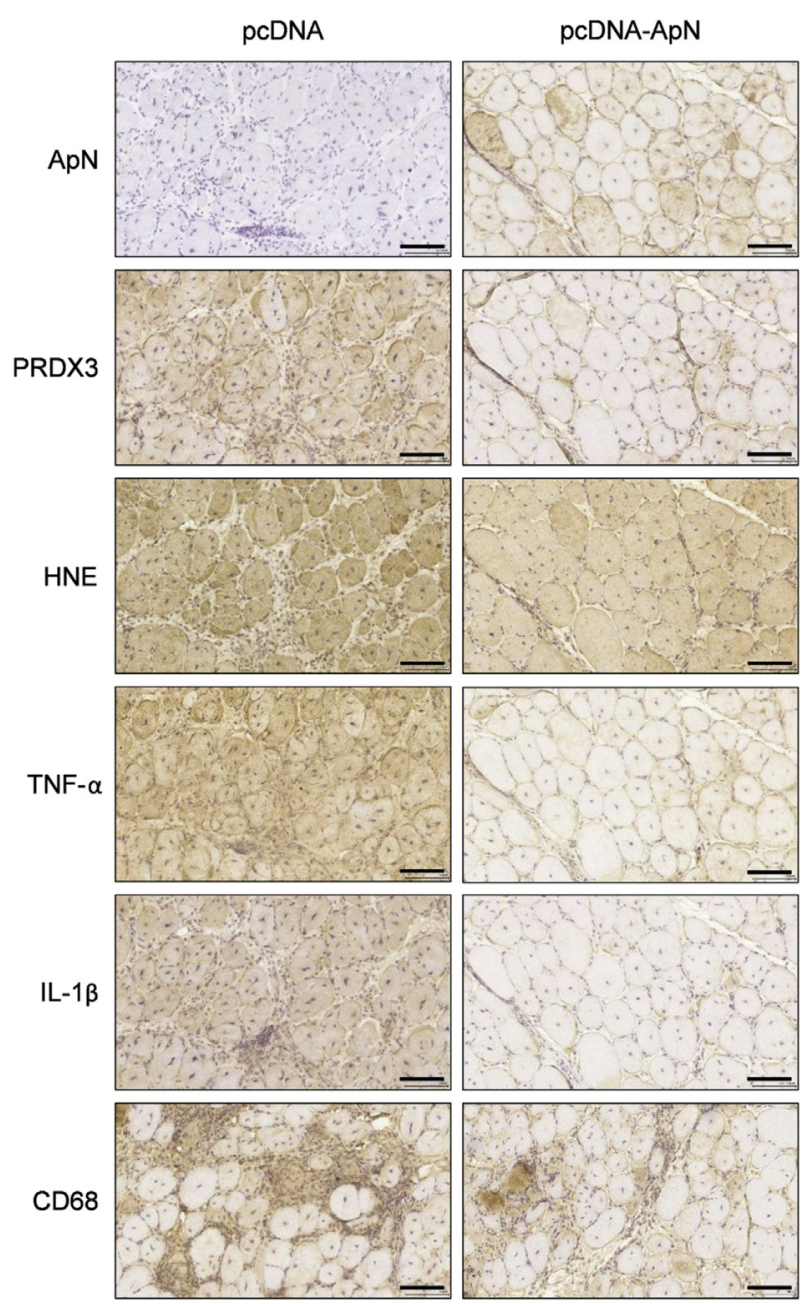

Figure 3 Effects of adiponectin gene electrotransfer on different markers of oxidative stress and inflammation in muscles of $\mathrm{mdx}-\mathrm{KO}$ mice. $\mathrm{mdx}-\mathrm{KO}$ mice were injected and electroporated with an ApN CDNA containing-plasmid in one tibialis anterior (TA), a control plasmid was used for the contralateral muscle. Mice were sacrificed 12 days after. ApN was only detected in the TA injected/electroporated with the plasmid containing the ApN gene but not in the contralateral muscle or in circulation. Immunodetection was performed with specific antibodies directed against ApN, two oxidative stress markers [peroxiredoxin 3 (PRDX3) and 4-hydroxy2-nonenal (HNE)], two proinflammatory cytokines [tumor necrosis factor (TNF) $-\alpha$ and IL-1 $\beta]$, and one macrophage marker (CD68). $n=6$ mice per group. Scale bars $=100 \mu \mathrm{m}$.

indication on muscle force and resistance to fatigue. In this test, the time during which the mouse is suspended on a horizontal wire is measured. ${ }^{12}$ Both $\mathrm{KO}$ and mdx-KO mice fell down faster than their respective controls, WT, and mdx mice (Figure 1A). The second test can quantitatively measure the global force in limb muscles. ${ }^{13}$ Similarly, the strength demonstrated by the forelimb and hindlimb muscles of both $\mathrm{KO}$ and mdx-KO mice was significantly reduced (approximately 20\%) when compared to that of WT and mdx mice, respectively (Figure 1B).

Mice resistance to fatigue was then evaluated by an eccentric exercise also designed to investigate muscle injury. On the third and last day of the exercise, the distance (meters) covered by each mouse was measured. WT and KO mice practically covered the maximum distance $(100 \mathrm{~m})$, the running distance of $\mathrm{mdx}$ mice decreased drastically (approximately $30 \mathrm{~m}$ ), whereas the $\mathrm{mdx}-\mathrm{KO}$ mice were only able to go half that distance (approximately $17 \mathrm{~m}$ ) (Figure 1C).

\section{Effects of Adiponectin Deficiency on Skeletal Muscle Injury}

Muscle damage was first assessed by measuring the plasma activities of CK and LDH. Elevation of both CK and LDH in circulation indicates a breach in the muscle membrane and is thus associated with injury. CK and LDH activities, measured herein, were approximately sevenfold and approximately sixfold higher in mdx than in WT mice, respectively, and were further increased (approximately $25 \%$ and approximately $30 \%$, respectively) in $\mathrm{mdx}-\mathrm{KO}$ mice compared with regular mdx. Furthermore, even at basal state, KO mice had higher CK and LDH activities than WT mice (Figure 2, A and B).

Next, sarcolemmal integrity was more directly evaluated by using EBD. EBD extravasation was quantified in different muscle types after repeated downhill treadmill exercise (Figure 2C). All six different muscles showed a similar profile for EBD content. Muscles from KO mice displayed higher EBD content than those of WT mice. EBD content was markedly increased (approximately threefold to sixfold) in muscles from mdx mice compared to WT ones, and then increased furthermore (approximately 20\% to $50 \%$ ) in muscles from mdx-KO mice compared to mdx. Hence, ApN deficiency significantly increases injury of different muscle types.

\section{Effects of Muscle Electrotransfer of the Adiponectin Gene on Markers of Inflammation and 0xidative Stress in $\mathrm{mdx}-\mathrm{KO}$ Mice}

Herein, we bluntly tested the hypothesis that local administration of ApN could protect the muscles of mdx-KO mice against excessive inflammatory/oxidative responses. mdx-KO mice were subjected to muscular electrotransfer of the ApN gene: one TA muscle was injected with a plasmid containing the full $\mathrm{ApN}$ sequence (pcDNA-ApN), whereas the contralateral TA muscle received an empty copy of the same plasmid (pcDNA). Mice were sacrificed 12 days after.

We first show the labeling for ApN in the TA muscle that was injected with the pcDNA-ApN versus the lack of expression in the contralateral muscle (Figure 3). In addition, ApN remained undetectable in the plasma of $\mathrm{mdx}-\mathrm{KO}$ mice (data not shown). Muscle electrotransfer of the ApN gene significantly reduced the expression of two oxidative stress markers, peroxiredoxin 3 and 4-hydroxy-2-nonenal (Figure 3), by approximately 50\% and approximately $20 \%$, respectively, when compared with the contralateral 

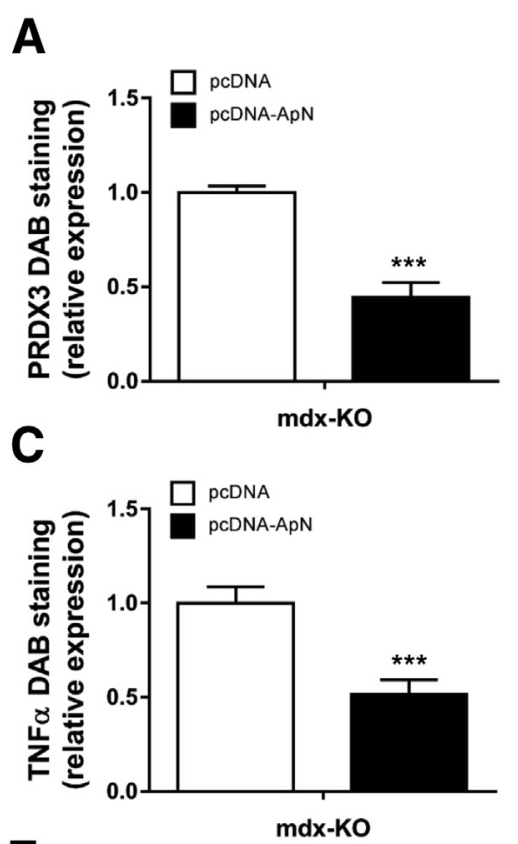

E

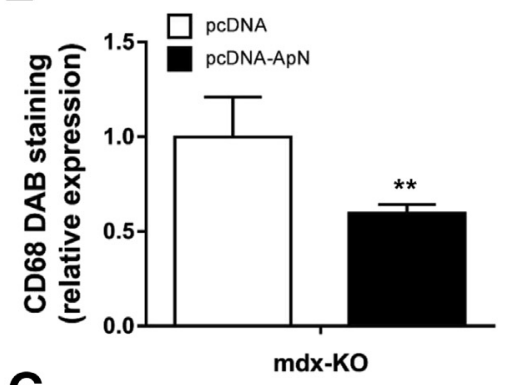

G

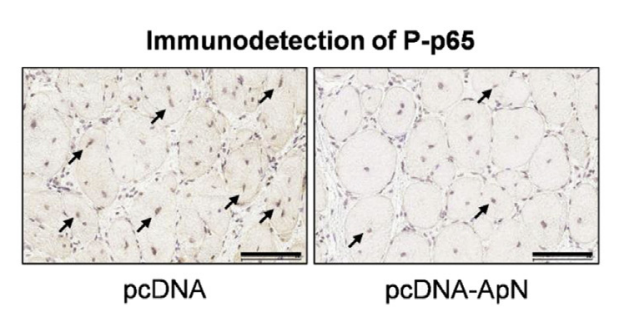

B
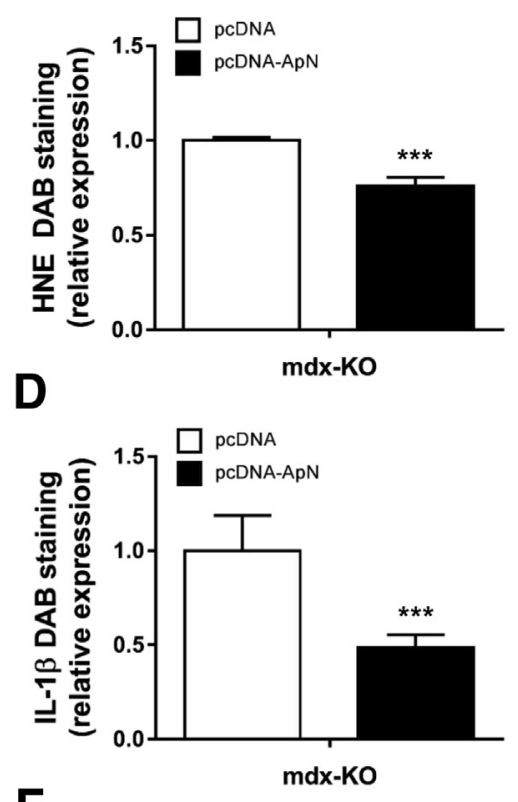

$\mathbf{F}$

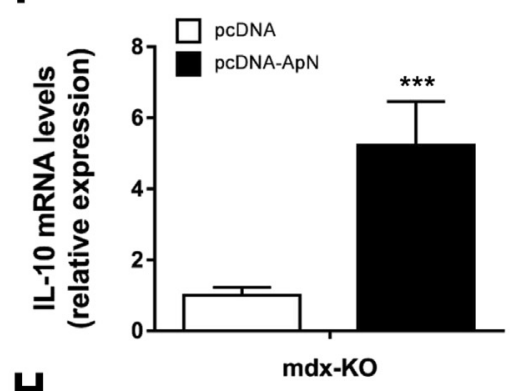

H

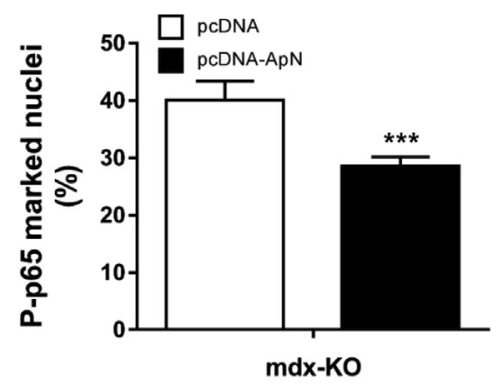

Figure 4 Quantification of markers of oxidative stress and inflammation in muscles of $\mathrm{mdx}-\mathrm{KO}$ mice after adiponectin gene electrotransfer. A-E: For each immunolabeling of Figure $3, A-E$, the percentage of 3,3'-diaminobenzidine (DAB) deposit areas was calculated within muscle fibers. F: mRNA levels of IL-10, an anti-inflammatory cytokine. mRNA levels were normalized to cyclophilin, and the subsequent ratios were presented as relative expression compared to the tibialis anterior (TA) that has received the empty pcDNA. G: Immunodetection of P-p65 (the active form of $\mathrm{NF}-\kappa \mathrm{B}$ ); some positive marked nuclei (brown color) are indicated by arrows. H: Quantification of P-p65 immunolabeling in myofiber nuclei (expressed as percentage of total nuclei). Data are expressed as means \pm SD $(\mathbf{A}-\mathbf{F}$ and $\mathbf{H}) . n=6$ mice per group $(\mathbf{A}-\mathbf{H}) .{ }^{* *} P<0.01,{ }^{* * *} P<0.001$ versus pcDNA. Scale bars $=100 \mu \mathrm{m}(\mathbf{G})$. HNE, 4-hydroxy-2-nonenal; $\mathrm{mdx}-\mathrm{KO}, \mathrm{mdx}$ mice with a general lack of ApN; PRDX3, peroxiredoxin 3; TNF- $\alpha$, tumor necrosis factor- $\alpha$. untreated TA muscle (Figure 4, A and B). Local administration of ApN also considerably reduced the expression of two major inflammatory cytokines (Figure 3), tumor necrosis factor- $\alpha$ and IL-1 $\beta$, by approximately $50 \%$ (Figure 4, C and D) when compared with the contralateral muscle.

A massive infiltration of macrophages (CD68, a marker of the proinflammatory M1 phenotype $)^{19}$ was also observed in the contralateral muscle of mdx-KO mice, whereas fewer M1 macrophages were detected in the muscle receiving the ApN gene (Figure 3). The area occupied by M1 macrophages was then measured and found to be approximately $40 \%$ smaller in the presence of $\mathrm{ApN}$ (Figure 4E). In addition, gene expression of IL-10, an anti-inflammatory cytokine that induces the switch from M1 to M2 macrophages, ${ }^{19}$ was significantly increased (fivefold) in the presence of ApN (Figure 4F).

Last, we tested the involvement of NF- $\kappa \mathrm{B}$, a pleiotropic transcription factor that regulates muscle inflammation as well as muscle regeneration/degeneration. ${ }^{3,20}$ We measured the nuclear translocation of NF- $\kappa \mathrm{B}$ by using an immunolabeling against P-p65 (the active phosphorylated form of $N F-\kappa B$ found in nuclei). The percentage of NF- $\kappa B-$ marked nuclei was determined and was found to be decreased by $>30 \%$ in the TA that received the ApN gene compared to the contralateral one (Figure 4, G and $\mathrm{H}$ ). 
A

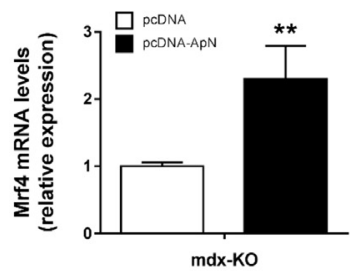

D

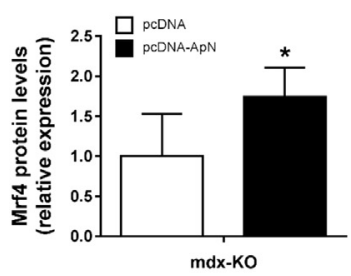

G

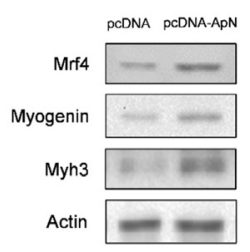

B

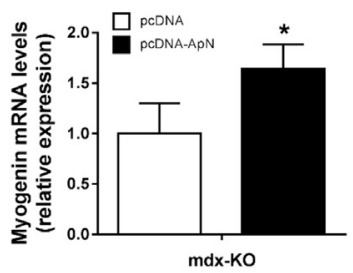

E

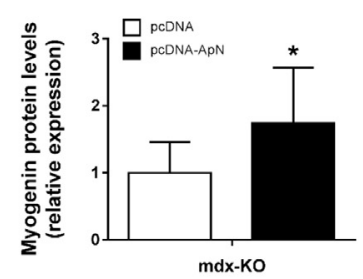

H

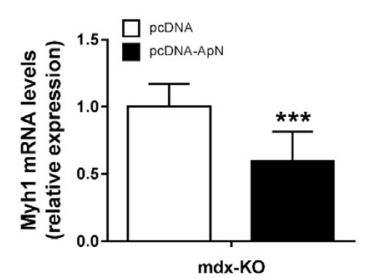

C

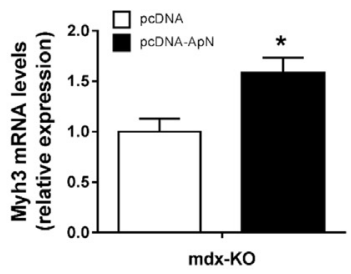

$\mathbf{F}$

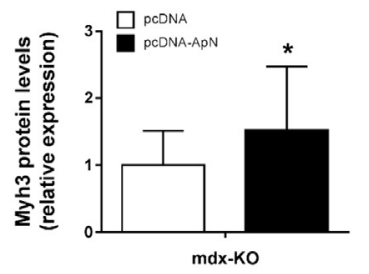

I

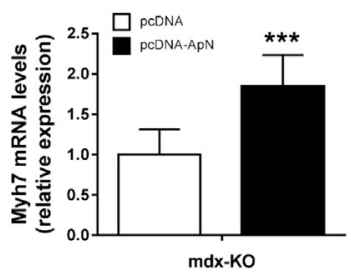

Figure 5 Effects of adiponectin gene electrotransfer on different markers of the myogenic program in $\mathrm{mdx}-\mathrm{KO}$ mice. mRNA levels of Mrf4 (A) and myogenin (B), two markers of muscle differentiation, and of Myh3 (eMyHC) (C), a marker of skeletal muscle regeneration. D-G: Western blot analysis for Mrf4, myogenin, and Myh3. H: mRNA levels of Myh1, a marker of fast twitch, glycolytic myofibers. I: mRNA levels of Myh7, a marker of slow twitch, oxidative myofibers. mRNA levels were normalized to cyclophilin, whereas protein levels were normalized to actin. The subsequent ratios were presented as relative expression compared with values of the contralateral muscle (ie, electroporated with an empty plasmid). Data are expressed as means $\pm \mathrm{SD}(\mathbf{A}-\mathbf{F}, \mathbf{H}$, and $\mathbf{I}) . n=6$ mice per group $(\mathbf{A}-\mathbf{I}) .{ }^{*} P<0.05,{ }^{*} P<0.01$, and ${ }^{* * *} P<0.001$ versus pcDNA. $\mathrm{mdx}-\mathrm{K} 0, \mathrm{mdx}$ mice with a general lack of ApN.
Effects of Muscle Electrotransfer of the Adiponectin Gene on the Myogenic Program

We have previously shown that $\mathrm{ApN}$ is capable of inducing myogenesis by activating main factors in the skeletal myogenic program.$^{10}$ Herein, we tested the expression of two major factors of muscle differentiation, Mrf4 and myogenin, as well as one key marker of muscle regeneration, Myh3 (alias embryonic myosin heavy chain). The expression of all three genes was approximately 1.5 -fold to approximately twofold higher in the TA muscle treated with ApN compared to the contralateral untreated one (Figure 5, A-C). Protein levels for all three markers were also significantly increased (approximately 50\%) in the TA muscle that received the ApN gene (Figure 5, D-G). Furthermore, the expression of Myh1, a marker of fast twitch glycolytic type II fibers, was decreased (approximately 40\%) in the TA that received the ApN gene compared to control TA, whereas the expression of Myh7, a marker of slow twitch oxidative type I fibers, was increased (approximately 80\%) (Figure 5, H and I), indicating a switch toward a more resistant oxidative phenotype in the presence of ApN.

\section{Discussion}

We and others have found that mdx mice display low circulating ApN levels (approximately $-40 \%$ to $-50 \%$ versus WT). ${ }^{10,21}$ When we crossed mdx mice, which exhibit muscular lesions since 2 weeks of age, ${ }^{22}$ with transgenic mice overexpressing circulating ApN from the same age, ${ }^{17}$ we showed that mere but early replenishment of ApN prevents the development of the mdx phenotype. ${ }^{10}$ Herein, we took an opposite approach and crossed mdx mice with ApNdeficient mice to test whether ApN depletion can adversely affect the mdx phenotype. More important, we showed that administration of ApN, once mid-stage dystrophic lesions are established, is able to reverse the disease, thereby strengthening the idea of a potential therapeutic role for this hormone.

Herein, we thus demonstrated that ApN deficiency worsened the global muscular force of mdx mice. In fact, mdx-KO mice demonstrated less muscular strength, as shown by the grip test, and less endurance, as shown by the wire test and the treadmill exercise, when compared to regular mdx. ApN deficiency also significantly aggravated muscle injury in mdx-KO mice compared to $\mathrm{mdx}$, as shown by higher plasma CK and LDH levels and higher extravasation of EDB, an indicator of fiber membrane damage, in all dystrophic muscles. These results mirror the improvement previously found in $\mathrm{mdx}$ mice overexpressing ApN. ${ }^{10}$ These data also fit with other studies performed in a nondystrophic background, which reported lower peak tetanic forces in muscles of ApN-KO mice stimulated in $s i t u,{ }^{23}$ and decreased treadmill exercise endurance in mice with muscle-specific disruption of adiponectin receptor $1 .{ }^{9}$

Muscles of mdx-KO mice were next electroporated with the ApN gene to test whether local administration of ApN could be sufficiently powerful to exert protective effects in 
dystrophinopathies. ${ }^{5,6} \mathrm{We}$ used this technique as it allows a direct comparison between the treated and the untreated leg within the same mouse, without the interference of any other systemic confounding factors because of the action of the hormone on other tissues. Mere restoration of muscle ApN was sufficient to lighten oxidative stress and inflammation, as shown by reduced expression of several oxidative and inflammatory markers. ApN gene electrotransfer was also capable of inducing a shift in macrophage polarization, as shown by the reduced number of proinflammatory M1 macrophage infiltrates and the increased expression of the anti-inflammatory cytokine IL-10 produced by M2 macrophages. $^{7}$ The anti-inflammatory action of ApN could mostly be ascribed to reduced NF- $\mathrm{BB}$ activation (this study ${ }^{7}$ ), mainly via the adiponectin receptor 1/AMP-activated protein kinase/Sirtuin 1/peroxisome proliferator-activated receptor- $\gamma$ coactivator- $1 \alpha$ signaling pathway. ${ }^{10} \mathrm{NF}-\kappa \mathrm{B}$, a master regulator of inflammation, is well known to play a critical role in the progression of DMD and suppressing its activity improved muscle function in mdx mice. ${ }^{3,24}$

Besides its anti-inflammatory and antioxidative stress actions, ApN also helps to improve the state of the skeletal muscle by boosting the myogenic program. ApN has been reported to stimulate muscle regeneration by activating satellite cells $\mathrm{s}^{25}$ and by increasing the expression of several markers involved in myoblast differentiation and fusion. ${ }^{10,26}$ Herein, local administration of ApN up-regulated the expression of two regulators of muscle differentiation (Mrf4 and myogenin) and of one key marker of muscle regeneration (Myh3), which is in agreement with our previous data. ${ }^{10}$ Furthermore, Myh1 levels were halved in the presence of ApN, whereas Myh7 levels were doubled, thus indicating a switch toward a more resistant oxidative fiber type. This switch resulting from peroxisome proliferatoractivated receptor- $\gamma$ coactivator- $1 \alpha$ activation may contribute to the increase in muscle force and endurance as well as to the protection against muscle damage. ${ }^{27,28}$

Taken together, all of these data indicate that by several mechanisms, ApN can protect the skeletal muscle, in an autocrine/paracrine manner, and thus rescue and reverse the dystrophic phenotype once it is settled.

Up to now, corticoid therapy is the only medication widely used in DMD. Data from randomized controlled trials indicate that it improves muscle strength and function in the short-term (12 months) and strength up to 2 years. ${ }^{29}$ These beneficial effects have been mostly ascribed to reduced inflammation. ${ }^{30}$ However, adverse effects must be considered: they include weight gain, growth retardation, cushingoid appearance as well as fractures, hypertension, and glucose intolerance. ${ }^{31,32} \mathrm{ApN}$ could therefore be a strong alternate candidate for DMD therapy because it is also known to exert powerful protective effects against obesity, hypertension, and glucose intolerance, all common adverse effects of glucocorticoids. ${ }^{33}$ So far, it is still unclear whether ApN levels are decreased in DMD boys, as described in mdx mice. Two studies (Hathout et $\mathrm{al}^{21}$ and
Cruz-Guzman Odel et $\mathrm{al}^{34}$ ) have reported circulating levels of ApN in Duchenne boys. However, both were lacking an appropriate control group and did not-or only partially - take into account the several confounding factors that may influence ApN levels (puberty stage, fat mass and insulin resistance, current treatment, etc). ${ }^{33}$ Yet, if it turned out that ApN levels were not decreased in DMD boys, ApN could still be proposed at supraphysiological concentrations, as it is the case for insulin in type 2 diabetes.

This study will help us to better understand ApN actions in regard to muscle protection, and hopefully will pave the way toward a novel pharmacological approach for neuromuscular disorders.

\section{Acknowledgments}

We thank Prof. Philippe Gailly and Dr. Olivier Schakman for providing the necessary equipment and the know-how for the in vivo functional tests.

\section{References}

1. Dalkilic I, Kunkel LM: Muscular dystrophies: genes to pathogenesis. Curr Opin Genet Dev 2003, 13:231-238

2. Blake DJ, Weir A, Newey SE, Davies KE: Function and genetics of dystrophin and dystrophin-related proteins in muscle. Physiol Rev 2002, 82:291-329

3. Acharyya S, Villalta SA, Bakkar N, Bupha-Intr T, Janssen PM, Carathers M, Li ZW, Beg AA, Ghosh S, Sahenk Z, Weinstein M, Gardner KL, Rafael-Fortney JA, Karin M, Tidball JG, Baldwin AS, Guttridge DC: Interplay of IKK/NF-kappaB signaling in macrophages and myofibers promotes muscle degeneration in Duchenne muscular dystrophy. J Clin Invest 2007, 117:889-901

4. Ouchi N, Walsh K: Adiponectin as an anti-inflammatory factor. Clin Chim Acta 2007, 380:24-30

5. Jortay J, Senou M, Abou-Samra M, Noel L, Robert A, Many MC, Brichard SM: Adiponectin and skeletal muscle: pathophysiological implications in metabolic stress. Am J Pathol 2012, 181:245-256

6. Jortay J, Senou M, Delaigle A, Noel L, Funahashi T, Maeda N, Many MC, Brichard SM: Local induction of adiponectin reduces lipopolysaccharide-triggered skeletal muscle damage. Endocrinology 2010, 151:4840-4851

7. Luo Y, Liu M: Adiponectin: a versatile player of innate immunity. J Mol Cell Biol 2016, 8:120-128

8. Yamauchi T, Nio Y, Maki T, Kobayashi M, Takazawa T, Iwabu M, Okada-Iwabu M, Kawamoto S, Kubota N, Kubota T, Ito Y, Kamon J, Tsuchida A, Kumagai K, Kozono H, Hada Y, Ogata H, Tokuyama K, Tsunoda M, Ide T, Murakami K, Awazawa M, Takamoto I, Froguel P, Hara K, Tobe K, Nagai R, Ueki K, Kadowaki T: Targeted disruption of AdipoR1 and AdipoR2 causes abrogation of adiponectin binding and metabolic actions. Nat Med 2007, 13:332-339

9. Iwabu M, Yamauchi T, Okada-Iwabu M, Sato K, Nakagawa T, Funata M, Yamaguchi M, Namiki S, Nakayama R, Tabata M, Ogata H, Kubota N, Takamoto I, Hayashi YK, Yamauchi N, Waki H, Fukayama M, Nishino I, Tokuyama K, Ueki K, Oike Y, Ishii S, Hirose K, Shimizu T, Touhara K, Kadowaki T: Adiponectin and AdipoR1 regulate $\mathrm{PGC}-1 \mathrm{alpha}$ and mitochondria by $\mathrm{Ca}(2+)$ and AMPK/SIRT1. Nature 2010, 464:1313-1319

10. Abou-Samra M, Lecompte S, Schakman O, Noel L, Many MC Gailly P, Brichard SM: Involvement of adiponectin in the pathogenesis of dystrophinopathy. Skelet Muscle 2015, 5:25 
11. Maeda N, Shimomura I, Kishida K, Nishizawa H, Matsuda M, Nagaretani H, Furuyama N, Kondo H, Takahashi M, Arita Y, Komuro R, Ouchi N, Kihara S, Tochino Y, Okutomi K, Horie M, Takeda S, Aoyama T, Funahashi T, Matsuzawa Y: Diet-induced insulin resistance in mice lacking adiponectin/ACRP30. Nat Med 2002, 8:731-737

12. Zanou N, Shapovalov G, Louis M, Tajeddine N, Gallo C, Van Schoor M, Anguish I, Cao ML, Schakman O, Dietrich A, Lebacq J, Ruegg U, Roulet E, Birnbaumer L, Gailly P: Role of TRPC1 channel in skeletal muscle function. Am J Physiol Cell Physiol 2010, 298: C149-C162

13. Mignion L, Magat J, Schakman O, Marbaix E, Gallez B, Jordan BF: Hexafluorobenzene in comparison with perfluoro-15-crown-5-ether for repeated monitoring of oxygenation using $19 \mathrm{~F} \mathrm{MRI}$ in a mouse model. Magn Reson Med 2013, 69:248-254

14. Hamer PW, McGeachie JM, Davies MJ, Grounds MD: Evans Blue Dye as an in vivo marker of myofibre damage: optimising parameters for detecting initial myofibre membrane permeability. J Anat 2002, 200:69-79

15. Wooddell CI, Zhang G, Griffin JB, Hegge JO, Huss T, Wolff JA: Use of Evans blue dye to compare limb muscles in exercised young and old mdx mice. Muscle Nerve 2010, 41:487-499

16. Brussee V, Tardif F, Tremblay JP: Muscle fibers of mdx mice are more vulnerable to exercise than those of normal mice. Neuromuscul Disord 1997, 7:487-492

17. Bauche IB, Ait El Mkadem S, Rezsohazy R, Funahashi T, Maeda N, Miranda LM, Brichard SM: Adiponectin downregulates its own production and the expression of its AdipoR2 receptor in transgenic mice. Biochem Biophys Res Commun 2006, 345:1414-1424

18. Leyens G, Donnay I, Knoops B: Cloning of bovine peroxiredoxinsgene expression in bovine tissues and amino acid sequence comparison with rat, mouse and primate peroxiredoxins. Comp Biochem Physiol B Biochem Mol Biol 2003, 136:943-955

19. Tidball JG, Villalta SA: Regulatory interactions between muscle and the immune system during muscle regeneration. Am J Physiol Regul Integr Comp Physiol 2010, 298:R1173-R1187

20. Langen RC, Van Der Velden JL, Schols AM, Kelders MC, Wouters EF, Janssen-Heininger YM: Tumor necrosis factor-alpha inhibits myogenic differentiation through $\mathrm{MyoD}$ protein destabilization. FASEB J 2004, 18:227-237

21. Hathout Y, Marathi RL, Rayavarapu S, Zhang A, Brown KJ, Seol H, Gordish-Dressman H, Cirak S, Bello L, Nagaraju K, Partridge T, Hoffman EP, Takeda S, Mah JK, Henricson E, McDonald C: Discovery of serum protein biomarkers in the mdx mouse model and cross-species comparison to Duchenne muscular dystrophy patients. Hum Mol Genet 2014, 23:6458-6469
22. Porter JD, Khanna S, Kaminski HJ, Rao JS, Merriam AP, Richmonds CR, Leahy P, Li J, Guo W, Andrade FH: A chronic inflammatory response dominates the skeletal muscle molecular signature in dystrophin-deficient mdx mice. Hum Mol Genet 2002, 11:263-272

23. Krause MP, Liu Y, Vu V, Chan L, Xu A, Riddell MC, Sweeney G, Hawke TJ: Adiponectin is expressed by skeletal muscle fibers and influences muscle phenotype and function. Am J Physiol Cell Physiol 2008, 295:C203-C212

24. Siegel AL, Bledsoe C, Lavin J, Gatti F, Berge J, Millman G, Turin E, Winders WT, Rutter J, Palmeiri B, Carlson CG: Treatment with inhibitors of the NF-kappaB pathway improves whole body tension development in the mdx mouse. Neuromuscul Disord 2009, 19:131-139

25. Fiaschi T, Giannoni E, Taddei ML, Chiarugi P: Globular adiponectin activates motility and regenerative traits of muscle satellite cells. PLoS One 2012, 7:e34782

26. Fiaschi T, Cirelli D, Comito G, Gelmini S, Ramponi G, Serio M, Chiarugi P: Globular adiponectin induces differentiation and fusion of skeletal muscle cells. Cell Res 2009, 19:584-597

27. Chalkiadaki A, Igarashi M, Nasamu AS, Knezevic J, Guarente L: Muscle-specific SIRT1 gain-of-function increases slow-twitch fibers and ameliorates pathophysiology in a mouse model of duchenne muscular dystrophy. PLoS Genet 2014, 10:e1004490

28. Ljubicic V, Burt M, Lunde JA, Jasmin BJ: Resveratrol induces expression of the slow, oxidative phenotype in $\mathrm{mdx}$ mouse muscle together with enhanced activity of the SIRT1-PGC-1alpha axis. Am J Physiol Cell Physiol 2014, 307:C66-C82

29. Matthews E, Brassington R, Kuntzer T, Jichi F, Manzur AY: Corticosteroids for the treatment of Duchenne muscular dystrophy. Cochrane Database Syst Rev 2016, 5:CD003725

30. Reeves EK, Rayavarapu S, Damsker JM, Nagaraju K: Glucocorticoid analogues: potential therapeutic alternatives for treating inflammatory muscle diseases. Endocr Metab Immune Disord Drug Targets 2012, 12:95-103

31. Beytia Mde L, Vry J, Kirschner J: Drug treatment of Duchenne muscular dystrophy: available evidence and perspectives. Acta Myol 2012, 31:4-8

32. Manzur AY, Kuntzer T, Pike M, Swan A: Glucocorticoid corticosteroids for Duchenne muscular dystrophy. Cochrane Database Syst Rev 2008, 2:CD003725

33. Maury E, Brichard SM: Adipokine dysregulation, adipose tissue inflammation and metabolic syndrome. Mol Cell Endocrinol 2010, $314: 1-16$

34. Cruz-Guzman Odel R, Rodriguez-Cruz M, Escobar Cedillo RE: Systemic inflammation in Duchenne muscular dystrophy: association with muscle function and nutritional status. Biomed Res Int 2015, 2015:891972 